\title{
Do sonho à realização: pedagogia empreendedora, empresariamento da educação e racionalidade neoliberal $^{1}$
}

\author{
Alexandre Alves ${ }^{2}$ \\ ORCID: 0000-0002-0810-650X \\ Viviane Klaus ${ }^{2}$ \\ ORCID: 0000-0002-6382-8089 \\ Carine Bueira Loureiro ${ }^{3}$ \\ ORCID: 0000-0002-3329-2535
}

\section{Resumo}

Nas últimas décadas, as reformas educacionais têm se baseado cada vez mais na lógica do mercado e na norma neoliberal de um sujeito autorregulado, flexível e empreendedor. No Brasil, a partir de diversas parcerias público-privadas, difundiu-se a chamada "pedagogia empreendedora", que procura utilizar o dispositivo escolar para disseminar a cultura do empreendedorismo entre crianças e jovens. Informada pela racionalidade econômica neoliberal, essa forma pedagógica sustenta que a adoção de uma atitude empreendedora em todas as esferas da vida é a chave para realizar objetivos como autorrealização, bem-estar material e satisfação pessoal. De acordo com essa lógica, para se adaptar a uma economia em contínua mudança e cada vez mais competitiva, é necessário que o indivíduo aprenda a ser autor e protagonista de sua própria vida, responsabilizando-se pelo aprendizado permanente das competências e habilidades demandadas pelo mercado. Para realizar este ensaio, consideramos estudos sobre a pedagogia empreendedora no Brasil, além de programas específicos e parcerias público-privadas, tendo como sustentação a teoria social contemporânea. Os resultados encontrados não têm como intenção representar a totalidade de ações na área da educação empreendedora no Brasil, mas apontar a disseminação do empreendedorismo como um modelo normativo que incita o sujeito a se conceber como uma empresa e a aceitar riscos, segundo uma racionalidade atuarial, que responsabiliza o estudante por sua própria formação, seu sucesso ou fracasso. Assim, a pedagogia empreendedora não só vende uma ilusão, mas reduz o espaço para formas alternativas de conceber a educação como direito do cidadão e bem comum.

\section{Palavras-chave}

Aprendizagem - Empreendedorismo - Neoliberalismo.

1- Este ensaio contou com o apoio da Coordenação de Aperfeiçoamento de Pessoal de Nível Superior (CAPES) e com o Conselho Nacional de Desenvolvimento Científico e Tecnológico (CNPq).

2- Universidade do Vale do Rio dos Sinos (UNISINOS), São Leopoldo, Rio Grande do Sul, Brasil. Contatos: sandoralves@gmail.com; viviklaus@unisinos.br

3- Instituto Federal do Rio Grande do Sul (IFRS). Porto Alegre, Rio Grande do Sul, Brasil. Contato: loureirocarine@gmail.com 


\title{
From dream to achievement: entrepreneurial pedagogy, making education entrepreneurial, and neoliberal rationality
}

\begin{abstract}
Over the last decades, educational reforms have increasingly been based on the Market logic and the neoliberal rule of self-regulated, flexible and entrepreneurial individual. In Brazil, stemming from several public-private partnerships the idea of the so-called "entrepreneurial pedagogy" spread seeking to utilize the school device to disseminate the culture of entrepreneurship among children and young people. Informed by the neoliberal economic rationality, such pedagogical form argues that by adopting an entrepreneurial attitude in all spheres of life is the key to achieve objectives such as self-fulfillment, material welfare and personal satisfaction. According to this logic, in order to adapt to an everchanging and increasingly competitive economy, the individual must learn to be the author and leading actor/actress of their own life, taking responsibility for permanently learning the competences and skill demanded by the market. To carry out this essay, contemplated the studies on entrepreneurial pedagogy in Brazil, as well as specific programs and publicprivate partnerships, supported by contemporary social theory. Findings are not intended to represent the totality of actions in the field of education in Brazil, but rather point to the spread of entrepreneurship as a normative model that encourages the individual to conceive him/herself as a company and to take risks, according to an actuarial rationality, which the student responsible for their training, their success or failure. Thus, the entrepreneurial pedagogy not only sells an illusion but also reduces the space for alternative ways of conceiving education as a citizen's right and as common good.
\end{abstract}

\section{Keywords}

Learning - Entrepreneurship - Neoliberalism.

\section{Introdução}

As reformas educacionais e as práticas pedagógicas no Brasil atual são cada vez mais pautadas pela lógica do mercado. Enquanto processo não só objetivo, mas também subjetivo e normativo, o mercado passa a pautar nossos modos de vida e padrões de comportamento de uma forma geral. Na área da educação, a mentalidade empresarial adentra as instituições, desde a educação básica até o ensino superior, a partir de políticas 
educacionais e de programas e/ou projetos elaborados e desenvolvidos por instituições do Terceiro Setor, do Sistema $\mathrm{S}^{4}$, assim como por empresas e fundações privadas.

0 objetivo deste estudo é analisar a racionalidade e os pressupostos que presidem essa cultura empresarial, que tem modelado as políticas e instituições de ensino no Brasil. Um papel de destaque é dado à análise da pedagogia empreendedora, cujo objetivo é utilizar o dispositivo escolar para disseminar na sociedade a mentalidade empresarial. Também se analisam as parcerias público-privadas que se servem da pedagogia empreendedora para formar crianças e jovens empreendedores.

Para a problematização aqui desenvolvida, que tem um tom ensaístico, selecionamos um conjunto de materiais com o intuito de discutirmos a proliferação do empreendedorismo na Educação Básica. Para tal, contamos com estudos diversos realizados sobre o tema; com excertos de dois livros clássicos de Fernando Dolabela: Pedagogia Empreendedora (DOLABELA, 2003a) e Empreendedorismo, uma forma de ser (DOLABELA, 2003b); com um artigo intitulado Fazendo revolução no Brasil: a introdução da pedagogia empreendedora nos estágios iniciais da educação (DOLABELA; FILION, 2013); e com um mapeamento de alguns programas desenvolvidos no Brasil cujo foco é a formação de crianças e jovens empreendedores. Conforme já mencionado, a nossa intenção aqui não foi a de mapear, circunscrever e analisar a totalidade de estudos e programas sobre educação empreendedora, até porque consideramos que isso não seria possível. Como nos diz Ball (2014), as participações e novas vozes dentro dos discursos de políticas são multifacetadas, e as formas de relacionamento entre os diferentes atores que adentram o âmbito educacional são variadas, portanto, não temos aqui o objetivo de mapear as redes a partir das quais o empreendedorismo é disseminado. Nesta análise, partimos de alguns exemplos e de dois pressupostos: 1) que os materiais que selecionamos veiculam uma determinada concepção de educação que tem norteado muitas das intervenções e parcerias entre escolas e iniciativa privada; 2) que os enunciados que circulam a partir deles produzem um "efeito de verdade" no cotidiano escolar (FOUCAULT, 2018), visando a naturalizar uma determinada visão da educação e a reduzir o espaço para concepções alternativas.

Em pesquisa realizada sobre as parcerias estabelecidas entre escolas/empresas/ outras organizações por oito Secretarias Municipais de Educação e três Coordenadorias do Estado do Rio Grande do Sul, constatamos que a maior parte dos projetos e programas desenvolvidos por parcerias público-privadas nas escolas da região tinham como foco central a formação de crianças e de jovens empreendedores. Entre os principais proponentes de projetos/programas, estão a Junior Achievement (JA) e o Serviço Brasileiro de Apoio às Micro e Pequenas Empresas (Sebrae) - que, neste artigo, são os dois casos escolhidos para complementar e exemplificar a análise da pedagogia empreendedora. Além disso, apresentamos alguns dos programas desenvolvidos por mantenedores e apoiadores do

\footnotetext{
4- 0 Sistema S compreende um "conjunto de organizações das entidades corporativas voltadas para o treinamento profissional, assistência social, consultoria, pesquisa e assistência técnica, que além de terem seu nome iniciado com a letra S, têm raízes comuns e características organizacionais similares. Fazem parte do sistema S: Serviço Nacional de Aprendizagem Industrial (Senai); Serviço Social do Comércio (Sesc); Serviço Social da Indústria (Sesi); e Serviço Nacional de Aprendizagem do Comércio (Senac). Existem ainda os seguintes: Serviço Nacional de Aprendizagem Rural (Senar); Serviço Nacional de Aprendizagem do Cooperativismo (Sescoop); e Serviço Social de Transporte (Sest)". Disponível em: https://www12.senado.leg.br/noticias/glossario-legislativo/sistema-s. Acesso em: 26 mar. 2021.
} 
Movimento Todos pela Educaçã $0^{5}$ na área da formação de crianças e jovens empreendedores, e alguns dos estudos sobre o tema no Brasil.

Para exposição dessas análises, dividimos o artigo em três partes: na primeira, realizamos um breve histórico da figura do empreendedor e da cultura empreendedora, ressaltando sua crescente importância na passagem do capitalismo social keynesiano para o capitalismo neoliberal; na segunda parte, discutimos a ideia do mercado como processo de aprendizagem e sua conexão com a pedagogia empreendedora, que desloca o foco do processo educativo para o desenvolvimento de competências por parte do aluno-cliente; por fim, na terceira parte, analisamos a articulação entre o empreendedorismo como modelo normativo de conduta e as novas formas de gerencialização da vida, apontando as consequências, os riscos e as fragilidades implicados por esse modelo educacional, fundado numa racionalidade neoliberal.

\section{Capitalismo, subjetivação e cultura empreendedora}

0 valor dado à figura do empreendedor e à cultura empreendedora data do início do capitalismo industrial. Em 1803, em seu "Tratado de economia política”, o economista francês Jean-Baptiste Say já ressaltava a importância do empreendedor na indústria moderna: "O empreendedor da indústria é o principal agente da produção. As outras operações são indispensáveis para a criação dos produtos, mas é o empreendedor que as implementa, que lhes dá um impulso útil e tira valor delas." (SAY, 1848 apud DARDOT; LAVAL, 2016, p. 152). Na visão de Say, o empreendedor é aquele que faz a intermediação entre o especialista que produz o conhecimento e o operário que executa o projeto. Possuidor de virtudes como julgamento correto, senso prático, audácia e determinação, dele dependeria o sucesso das empresas e a prosperidade das nações.

Exemplos de grandes homens de negócio que criaram verdadeiros impérios comerciais a partir do fim do século XIX, como John D. Rockfeller e Andrew Carnegie, levaram o economista austríaco Joseph Schumpeter a teorizar a centralidade do empreendedor no processo de desenvolvimento econômico. Schumpeter é considerado o primeiro autor a elaborar uma teoria do empreendedorismo (LOPEZ-RUIZ, 2007, p. 112-135). Em sua obra o empreendedor é visto como um inovador que impulsiona o processo de "destruição criadora”, do qual depende o progresso econômico. Na visão de Schumpeter (2017), o empreendedor não se confunde nem com o dono do capital, nem com o administrador da firma. Ele é o indivíduo que inova, recombinando de maneiras inéditas os fatores de produção, inventando novas técnicas, novas formas de organização do processo produtivo, encontrando novas fontes de matérias-primas ou abrindo novos mercados. Devido à tendência à queda da taxa de lucro - que, para Schumpeter, é inerente à economia capitalista -, a atuação do empreendedor-inovador seria essencial por propulsionar a única maneira de contornar essa tendência, qual seja, a elevação permanente da produtividade do trabalho mediante a inovação contínua.

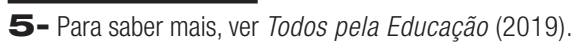


Autores da escola neoliberal austríaca conferiram uma nova dimensão à cultura empreendedora. Para Ludwig von Mises (2010) e Friedrich A. Hayek (1978), o empreendedorismo é o princípio de conduta mais essencial ao funcionamento da ordem capitalista. Diferentemente da perspectiva de Schumpeter, o empreendedor não é mais visto por eles como uma figura excepcional e criadora que rege o processo econômico, tal como um maestro conduz uma orquestra. Todos teriam dentro de si um potencial empreendedor, o qual estaria apenas esperando pelas ocasiões propícias para se manifestar. Essas ocasiões seriam fornecidas pelo mercado, que teria papel formativo para o sujeito empresarial, ensinando-o a se conduzir racionalmente na medida em que é exposto a situações de competição. Desse modo, o indivíduo empreendedor é visto por Mises e Hayek como aquele que não teme aventurar-se no jogo da concorrência e que aprende a usar a informação disponivel para buscar as melhores oportunidades de ganho e realização pessoal num mercado concorrencial.

Os neoliberais austríacos destacam a relevância do elemento subjetivo no processo econômico. Para eles, a economia é baseada mais na capacidade de escolha do indivíduo do que na maximização do interesse dos agentes. A livre escolha a partir da informação pertinente seria a própria condição de funcionamento de mercados competitivos. Consequentemente, toda intervenção do Estado sobre o funcionamento da economia seria danosa, por distorcer a informação e deturpar o jogo livre da concorrência. Na visão dos neoliberais austríacos e de seus herdeiros intelectuais da escola de Chicago (Israel Kirzner, Milton Friedman, Gary Becker etc.), só a economia de mercado é capaz de estimular e dar livre curso ao espírito empreendedor que cada homem já traz dentro de si (DARDOT e LAVAL, 2016).

Nessa concepção, o empreendedorismo deixa de ser um conjunto de virtudes que somente os grandes homens de negócios possuiriam e passa a ser um modelo de comportamento extensível a todos, de modo que deveria ser perseguido não só nos negócios, mas em todos os aspectos da vida.

A difusão desse modelo do sujeito empreendedor ocorreu em paralelo à transformação estrutural da economia e do Estado a partir dos anos 1980. 0 advento da nova economia, com a convergência da revolução tecnológica e do processo de globalização, transformou a estrutura das organizações. As empresas do período áureo do capitalismo keynesiano (1930-1960) eram estruturas piramidais e hierárquicas, organizadas de maneira rígida e centralizada. Os trabalhadores, nesse tipo de organização, normalmente faziam carreira numa única instituição, galgando um a um os degraus de sua hierarquia interna, tendo, muitas vezes, garantia de emprego vitalício. Nesse contexto, formavam-se fortes vínculos de solidariedade dentro dos grupos de trabalho e relações de lealdade com a instituição. Além disso, os altos impostos cobrados pelo Estado permitiam financiar o sistema de seguridade social, assegurando uma série de benefícios e garantias, ao menos nas economias mais industrializadas do Ocidente.

As tecnologias digitais e de comunicação permitiram que as novas organizações se tornassem mais flexíveis e menos hierárquicas, possibilitando fragmentar os processos de produção e terceirizar partes inteiras da cadeia produtiva para países que ofereciam mão de obra qualificada por salários bem inferiores. Nesse sentido, as mudanças legislativas 
e institucionais a partir dos governos neoliberais de Reagan nos EUA e Thatcher na Grã-Bretanha, generalizaram os contratos flexíveis de trabalho (trabalho temporário, domiciliar, intermitente ou em tempo parcial) e reduziram o investimento do Estado em programas e mecanismos de seguridade social. Essas mudanças levaram ao aumento da competição entre as empresas; à fragmentação social, com o enfraquecimento dos sindicatos; à individualização dos desempenhos nas firmas e ao apagamento da divisão entre vida privada e vida profissional (SENNETT, 2008).

Nesse contexto, o welfarestate era acusado pela nova direita norte-americana e europeia de fomentar estruturas burocráticas caras, ineficientes e paternalistas, que induziam à passividade e à dependência dos cidadãos. No seu lugar, disseminou-se a "cultura empreendedora", fundada no pensamento econômico neoliberal e nas teorias da gestão, que procuram estimular indivíduos autônomos, ativos, dotados de poder de escolha. A partir dos anos 1970 e 1980, as teorias da gestão poriam uma ênfase cada vez maior em valores como empreendedorismo, autonomia e inovação como bases para o surgimento de um "novo espírito do capitalismo", baseado em organizações mais flexíveis e grupos de trabalho horizontalizados e em rede (BOLTANSKI; CHIAPELLO, 2009). Na nova economia, a adoção de um comportamento proativo, independente e empreendedor é vista pelos teóricos da gestão como essencial para o sucesso, a produtividade e a competitividade das organizações. Peter Drucker, por exemplo, vê o empreendedor como aquele que não teme a mudança, que é capaz de se adaptar rapidamente a novas conjunturas e sabe explorar as oportunidades disponíveis para criar e inovar. Drucker preconiza o advento de uma nova sociedade, afluente e dinâmica, por meio da difusão em larga escala da cultura empreendedora (DRUCKER, 2012).

A escola, instituição fundamental de formação e produção de subjetividade, é um dos meios privilegiados escolhidos para fabricar esse novo sujeito e disseminar a cultura empreendedora por toda a sociedade (LAVAL, 2004). Diversas instituições como o Fundo Monetário Internacional (FMI), o Banco Mundial e a Organização para a Cooperação e Desenvolvimento Econômico (OCDE), nas últimas décadas, têm desenvolvido uma série de programas e iniciativas para transformar o sistema de ensino e tornar o "espírito de empreendedorismo" um elemento importante dos currículos e programas escolares.

\section{Mercado, aprendizagem e pedagogia empreendedora}

Os discursos reformistas alinhados à racionalidade econômica neoliberal e ao imperativo empreendedor têm pautado, de forma intensa, a agenda educacional contemporânea. Vários desses discursos versam sobre a necessidade de formar crianças e jovens para a economia do século XXI, o que implica a constituição de sujeitos capazes de participar ativamente da lógica da concorrência, colocada em circulação a partir de uma nova concepção de mercado como "um processo de descoberta e aprendizado que modifica os sujeitos, ajustando-os uns aos outros” (DARDOT; LAVAL, 2016, p. 139).

Apesar de muitas vezes ser entendido, de maneira simplificada, como um dado estático e imutável, o conceito de mercado se modificou ao longo da história do capitalismo (ROSANVALLON, 2002). No liberalismo clássico, o mercado apontava para um ambiente 
"natural", por meio do qual circulavam as mercadorias e se davam as trocas entre os agentes econômicos. Já na racionalidade econômica neoliberal, mercado é uma realidade cambiante e designa não um meio natural, mas um processo que tem dimensões objetivas e subjetivas, cuja coordenação é complexa e que utiliza competências e motivações psicológicas específicas dos agentes envolvidos. Desse modo, o mercado deixa de ser definido como um processo autorregulador (isto é, que conduz ao equilíbrio perfeito entre as forças econômicas) e torna-se uma dinâmica autocriadora, ou seja, capaz de se autogerar no tempo por intermédio da ação dos sujeitos. Nesse sentido, Dardot e Laval estão corretos em ressaltar o elemento subjetivo e formativo do mercado na racionalidade neoliberal, que pode ser definido como "um processo subjetivo autoeducador e autodisciplinador, pelo qual o indivíduo aprende a se conduzir" (DARDOT; LAVAL, 2016, p. 140).

0 mercado, assim, seria o dispositivo que induz a autoformação dos agentes econômicos - autoformação entendida como capacidade de "aprender a aprender" -, que passa a ser fomentada a partir da articulação de um conjunto de práticas de produção de "um sujeito ativo, um sujeito aprendente, esse indivíduo que, por sua própria experiência, por sua própria atividade, aprende o que precisa para viver e ser feliz" (MARÍN-DÍAZ, 2015, p. 203, grifos nossos).

Essa visão do mercado como processo ativo e dinâmico de aprendizagem se reflete numa série de documentos e políticas educacionais das últimas décadas. No "Relatório para a Unesco da Comissão Internacional sobre Educação no século XXI" (conhecido como Relatório Delors), os quatro pilares da educação - "aprender a conhecer", "aprender a fazer", "aprender a viver juntos"|"aprender a viver com os outros" e "aprender a ser" estão relacionados com a mudança de ênfase da noção de qualificação para a noção de competência, resultante da desmaterialização e da flexibilização do trabalho, assim como da crescente importância dos serviços entre as atividades assalariadas (DELORS, 2012). No Relatório Delors, o conceito de aprendizagem é colocado no centro do processo educacional e objetiva potencializar a autoformação e a autocondução dos sujeitos econômicos, que devem tornar-se sujeitos autorregulados. Segundo Delors, "existe uma questão comum aos países desenvolvidos e em desenvolvimento: como aprender a comportar-se eficazmente em uma situação de incerteza; como participar na criação do futuro?” (DELORS, 2012, p. 78). Nessa lógica, os conhecimentos de que cada indivíduo dispõe e a sua capacidade de readaptação - o "aprender a aprender" - é que possibilitariam lidar com as incertezas e instabilidades típicas da nova racionalidade neoliberal ${ }^{6}$.

A escola enquanto ambiente privilegiado de formação de crianças e jovens é acionada constantemente, a partir do imperativo da aprendizagem permanente para o mercado, na tarefa de impulsionadora do desenvolvimento de competências para a economia do século XXI. Empresários, economistas, profissionais da área de Gestão e Negócios, de um modo geral, veem na escola um espaço profícuo para o desenvolvimento de um sujeito empreendedor, pois, como ressaltaram Dardot e Laval (2016),

6- 0 mercado enquanto um processo subjetivo de "autocriação", disciplina, formação, condução e educação por toda a vida "é um desses instrumentos que andam sozinhos, justamente porque coordena os trabalhos especializados utilizando otimamente os conhecimentos dispersos" (DARD0T; LAVAL, 2016, p. 142). 
[...] se o mercado é um processo de aprendizado, se o fato de aprender é um fator fundamental do processo subjetivo de mercado, o trabalho de educação realizado por economistas pode e deve contribuir para a aceleração dessa autoformação do sujeito. A cultura de empresa e o espírito de empreendimento podem ser aprendidos desde a escola, do mesmo modo que as vantagens do capitalismo sobre qualquer outra organização econômica. 0 combate ideológico é parte integrante do bom funcionamento da máquina. (DARDOT; LAVAL, 2016, p. 150-151).

Assim, preparar os estudantes para serem empreendedores em todas as áreas das suas vidas e em quaisquer atividades que escolherem desempenhar (DOLABELA, 2018), um dos fundamentos da pedagogia empreendedora ${ }^{7}$, ecoa nos programas educacionais, especialmente no Brasil, que, nas palavras de Dolabela e Filion (2013, p. 154-155) "enfrenta uma grande necessidade de educação empreendedora que permita que uma maior proporção do seu capital humano desenvolva o seu potencial empreendedor". Sem adotar uma educação empreendedora, complementam os autores, "continuará a ser negada a grandes segmentos da sociedade a oportunidade de gerar renda e experimentar a autorrealização”. (DOLABELA; FILION, 2013, p. 154-155). Segundo tal perspectiva, mais do que uma forma de assumir a si como uma empresa e um meio de garantir renda para prover as necessidades básicas e driblar o desemprego, por meio do empreendedorismo é que o indivíduo alcançará objetivos como autorrealização, satisfação pessoal e bem-estar material. A pedagogia empreendedora, portanto,

[...] desvincula o conceito de empreendedor de uma atividade específica e o relaciona a uma forma de ser - algo ligado a estilo de vida, visão de mundo, protagonismo, inovação, capacidade de produzir mudanças em si mesmo e no meio ambiente, meios e formas de buscar a autorrealização, incluindo padrões de reação diante de ambiguidades e incertezas. (DOLABELA, 2003a, p. 37).

A atividade pedagógica, neste caso, "vai se dedicar principalmente à conexão entre sonho e sua realização”. (DOLABELA, 2003a, p. 55). 0 objetivo é "estimular e preparar o aluno para sonhar"; ele "desenvolve um sonho, um futuro onde deseja chegar, estar ou ser". (DOLABELA, 2003a, p. 55). Para realizar esse sonho, ele "se vê motivado a aprender o necessário a esse objetivo”. (DOLABELA, 2003a, p. 55). Desta forma, para tornar seu sonho realidade,

0 estudante é estimulado a gerar conhecimentos sobre si mesmo, sobre o que deseja realizar no futuro e como construir os caminhos para isso. Assim o aluno é autor de si mesmo e aprende, como faz o empreendedor real, a buscar os conhecimentos necessários à realização do seu sonho. Através da construção da sua autopercepção o estudante toma consciência das suas limitações e se prepara para construir complementaridades, atraindo competências e pessoas para executarem o que ele não quer, não pode ou não sabe fazer. (DOLABELA; FILION, 2013, p. 157).

Portanto, a pedagogia empreendedora desloca o foco no processo educativo do ensino para a aprendizagem e, correlativamente, põe o acento no protagonismo do aluno,

7- Para saber mais sobre o tema, sugere-se a leitura de Mengue (2019) que, em sua dissertação de Mestrado, problematiza e discute de forma aprofundada a pedagogia empreendedora de Fernando Dolabela, que pode ser aplicada desde a Educação Infantil até o Ensino Superior, a partir da noção do sonho coletivo. 
visto como "cliente", e não na atividade do professor (BIESTA, 2018). A ideia é que "a situação de aprendizagem já não é assegurada na transmissão de conhecimentos por parte do professor, mas se apoia nas operações que cada jovem consegue realizar com as ferramentas de que dispõe" (SIBILIA, 2012, p. 125). 0 sentido da aprendizagem, desse modo, está no aprendiz, que se desloca da posição de aluno que aprende algo ensinado por alguém - no caso, pelo professor - para a de "protagonista do seu próprio destino" (DOLABELA; FILION, 2013, p. 136-13). Além disso, o protagonismo será alavancado pelos sonhos individuais, pois estes "implicam em pensamentos projetivos que permitem que as pessoas se tornem mais organizadas, identificando mais claramente o que precisam aprender" (DOLABELA; FILION, 2013, p. 141).

Assim, mais do que o aluno aprender alguma coisa por meio da condução pedagógica de um professor, o que está em jogo na pedagogia empreendedora é a atuação do indivíduo sobre si mesmo para desenvolver a capacidade de se aperfeiçoar e desempenhar um papel de destaque, na busca pela autorrealização. Cabe, portanto, a cada um desenvolver as habilidades necessárias para "transformar os seus sonhos em realidade" (DOLABELA; FILION, 2013, p. 135) e se tornar um indivíduo-empresa bem-sucedido nos negócios e na vida. 0 sonho estruturante, referido na teoria empreendedora dos sonhos, dá "origem e organização a um projeto de vida, articulando sinergicamente desejos, visão de mundo, valores, competências, preferências, autoestima” (DOLABELA, 2003a, p. 38).

Nesse sentido, o que importa, no processo educacional mobilizado pela pedagogia empreendedora é o desenvolvimento de características individuais, como criatividade, iniciativa, aptidão para a resolução de problemas, capacidade de adaptação, reflexão, flexibilidade, exercícios de responsabilidades e aptidão ao aprendizado. Em suma, o indivíduo-empresa precisa aprender a desenvolver certas disposições e atitudes, valores comportamentais e capacidade de ação - é a ideia de competências que é enfatizada no processo. Desse modo, a escola, como espaço que mais precocemente socializa e subjetiva a todos, torna-se um espaço potente para a disseminação de uma subjetividade empreendedora. Assim, torna-se cada vez mais comum a adoção de programas e projetos elaborados e mantidos por empresas privadas e organizações do terceiro setor, voltados para a implantação e o desenvolvimento da pedagogia empreendedora em escolas de educação básica.

\section{Empresariamento da educação como estratégia de disseminação da cultura empreendedora}

Conforme mencionado na introdução deste ensaio, apresentaremos na sequência alguns dados de pesquisa sobre parcerias escola/empresa com foco na formação de crianças e jovens empreendedores. A nossa intenção não é a de apresentar a totalidade de programas sobre o tema, até porque várias dessas ações em rede se desdobram e se pulverizam em outras, e assim sucessivamente. Como diz Ball (2014), "redes políticas são um tipo de 'social' novo, envolvendo tipos específicos de relações sociais, de fluxos e de movimentos" (BALL, 2014, p. 29). Não rastreamos aqui os fluxos com o intento de mapearmos uma rede de ações. 0 nosso intuito foi o de trazer alguns exemplos, pois o 
tema do empreendedorismo, de modo geral, conecta-se com a mentalidade empresarial característica do tempo em que vivemos.

Para a discussão desenvolvida, foi realizado o levantamento das pesquisas acadêmicas disponíveis no Banco de Teses e Dissertações da CAPES, no período de 2015 a 2019, a partir do descritor “empreendedorismo na educação”. Retornaram mais de 80 mil trabalhos. Destes, foram descartados aqueles que não estavam relacionados com práticas desenvolvidas na Educação Básica. A leitura dos resumos gerou um conjunto de 13 teses e dissertações cuja forma de abordagem da temática do empreendedorismo na educação interessava para a problematização desenvolvida neste ensaio. Entre os trabalhos analisados, onze deles defendem a disseminação da pedagogia empreendedora na Educação Básica - o que reforça nossas considerações acerca do modelo normativo que referimos.

Em pesquisa realizada por Klaus (2018) sobre as parcerias estabelecidas entre escolas/empresas/outras organizações por oito Secretarias Municipais de Educação e três Coordenadorias do Estado do Rio Grande do Sul, constatamos que a maior parte dos projetos e programas desenvolvidos pelos parceiros tem como foco central a formação de crianças e de jovens empreendedores. Entre os principais proponentes de projetos/programas, estão a Junior Achievement (JA) e o Sebrae. No caso da Junior Achievement, cuja missão é "inspirar e preparar jovens para terem sucesso em uma economia globalizada" (JA BRASIL, [2018?]), o número de crianças e jovens contemplados pelos Programas de 2010 a 2013 - 4 anos - chegou bem próximo do atingido de 1984 a 2009 - 25 anos anteriores -, resultando em um aumento de aproximadamente $477 \%$ de crianças e jovens envolvidos nos projetos. Na sua visão, a Junior pretende "ser parceira de empresas, educadores e gestores públicos em todo o mundo que buscam expandir a educação de jovens e o desenvolvimento econômico" (JA BRASIL, [2018?]).

Uma análise geral possibilita afirmar que os programas da JA possuem os seguintes objetivos: preparar o jovem para a inserção no mercado de trabalho, possibilitar que o jovem aprenda a administrar a sua própria vida e desenvolver o "espírito empreendedor", que se reflete nos modos de condução da vida. Segundo López-Ruiz (2007, p. 30, grifos nossos) "o empreendedorismo passou a ser a atitude de um povo, a atitude que se espera de um povo"; por isso, o

[...] "você S.A.”, não pode ser apenas você. Precisa-se de inúmeros vocês, indivíduos individuais - e daí a necessidade de uma configuração como o ensemble individualism para estabelecer os vínculos entre eles - que assumam um compromisso profundo com eles mesmos, com os investimentos feitos em si, com seu capital humano, com sua empresa. (LÓPEZ-RUIZ, 2007, p. 262, grifos nossos).

0 site da JA expressa em números a proliferação da educação empreendedora em escolas de ensino básico no Brasil. 0 total do número de estudantes, escolas e voluntários atingidos pelos programas da JA em três anos, de 2010 a 2013, é mais que o dobro quando comparado aos números totais dos vinte e cinco anos precedentes, de 1984 a 2009. No interstício de 2010 a 2013, a JA esteve presente em 8.861 escolas; dessas instituições, 1.440.378 estudantes participaram de programas de empreendedorismo, que contaram 
com 50.619 voluntários (JA BRASIL, [2018?]). Esses números correspondem a 73\% do número de escolas, 76\% do total de estudantes e 71\% do acumulado de voluntários ${ }^{8}$ que participaram dos programas da educação empreendedora da JA.

No caso do SEBRAE, o número de indivíduos contemplados nos programas relacionados à formação de crianças e jovens empreendedores também é expressivo. Até 2015, por exemplo, 170 mil alunos foram atendidos pelo Programa Pronatec Empreendedor ${ }^{9}$, e 600 mil pessoas foram contemplados pelo Programa Jovens Empreendedores Primeiros Passos $^{10}$ (SEBRAE, 2021a).

Entre mantenedores e apoiadores do Movimento Todos pela Educação, percebemse alguns projetos e ações no sentido de disseminar a cultura do empreendedorismo na Educação Básica. Entre eles, podemos citar: a Fundação Telefônica Vivo, com o Programa "Pense Grande"; o Instituto Natura em parceria com a Fundação Telefônica Vivo e o Laboratório de Inovação Educacional (LABI), que juntos desenvolvem o Programa "Inova Escola: Práticas para quem quer inovar na educação"; a Fundação La Caixa, com o Programa "Jovens empreendedores"; e a Fundação Educar DPaschoal, com o Programa "Academia Educar".

Foi justamente esse aumento expressivo de programas voltados ao empreendedorismo que nos mobilizou a problematizar a importância e os pressupostos normativos da pedagogia empreendedora, que

[...] toma o empreendedor como alguém capaz de gerar novos conhecimentos a partir de uma dada plataforma, constituída por 'saberes' acumulados na história de vida do indivíduo e que são os chamados 'quatro pilares da educação'. (DOLABELA, 2003a, p. 26).

Para Dolabela, o comportamento empreendedor é um processo de formação cíclico, que se retroalimenta constantemente e que exige do sujeito a capacidade de transformarse e readaptar-se permanentemente:

Empreender é essencialmente um processo de aprendizagem proativa, em que o indivíduo constrói e reconstrói ciclicamente a sua representação do mundo, modificando-se a si mesmo e ao seu sonho de autorrealização em processo permanente de autoavaliação e de autocriação. (DOLABELA, 2003a, p. 32).

Justamente porque o desenvolvimento de uma atitude empreendedora é um processo de aprendizado contínuo, como já destacavam os economistas neoliberais e teóricos da gestão analisados acima, para que o empreendedorismo seja um fenômeno de massa (DARDOT; LAVAL, 2016; LÓPEZ-RUIZ, 2007), os sujeitos devem desenvolver

8- Os percentuais foram calculados a partir dos dados que constam no site da JA (JA BRASIL, [2018?]).

9 - 0 objetivo do PRONATEC é "[...] trabalhar a Educação Empreendedora por meio da inserção de conteúdos em cursos PRONATEC, para que seja possível orientar os estudantes para as diferentes possibilidades no mundo do trabalho [...] Traz a perspectiva do autoemprego, além do desenvolvimento de competências empreendedoras que são fundamentais para a trabalhabilidade [...]" (SEBRAE, 2021a).

10- 0 JEPP destina-se "a fomentar a educação e a cultura empreendedora. 0 curso procura apresentar práticas de aprendizagem, considerando a autonomia do aluno para aprender, além de favorecer o desenvolvimento de atributos e atitudes necessários para a gestão da própria vida". (SEBRAE, 2021b). A visão do Programa baseia-se nos quatro pilares da educação. 
competências empreendedoras desde a infância. Isso é o que justifica e legitima as parcerias com as escolas e a estratégia de financiamento de programas voltados para crianças, jovens e adolescentes. 0 que é proposto é um verdadeiro modelo de subjetividade com forte caráter normativo, que visa a permitir novas formas de gestão e governo dos indivíduos. Segundo preconiza a racionalidade neoliberal, os sujeitos devem ser governados não por meio de coações externas, mas mediante sua própria capacidade de autorregulação e autocondução.

No próximo tópico, analisamos como esse modelo normativo tornou-se um verdadeiro imperativo que define os modos de subjetivação - ou seja, de relação consigo mesmo e com os outros - nas sociedades contemporâneas.

\section{O indivíduo empreendedor como modelo normativo e como modo de governo}

$\mathrm{Na}$ discussão que tecemos até aqui, procuramos pontuar como o imperativo do empreendedorismo extrapola as paredes das empresas e produz novas formas de ser e de estar no mundo. Mais especificamente, o vocabulário do empreendedorismo, segundo Rose (1998),

[...] não apenas designa um tipo de forma organizacional [...], mas também, de forma mais ampla, oferece uma imagem de um modo de atividade a ser incentivado em muitos cenários da vida a escola, a universidade, o hospital, os consultórios clínicos gerais, a fábrica e as estruturas de bem-estar social. (ROSE, 1998, p. 214).

Hoje, o empreendedor tornou-se um modelo de subjetividade onipresente nas sociedades contemporâneas. 0 indivíduo é chamado a atuar sobre si mesmo para se aperfeiçoar, se adaptar e se transformar continuamente, adquirindo as competências e capacidades que lhe permitirão valorizar-se como capital humano e realizar seus sonhos e anseios. 0 indivíduo empreendedor é visto, ao mesmo tempo, como provedor e administrador desse capital, devendo assumir os riscos inerentes à gestão de qualquer capital. Assim, ele deve desenvolver e demonstrar em seu cotidiano qualidades como autonomia, flexibilidade, responsabilidade, criatividade, inovação e autoeficácia. Na nova configuração da subjetividade, como mostra Bröckling (2016), o imperativo do empreendedorismo torna-se um verdadeiro campo de força que governa a vida, informa o pensamento e orienta os comportamentos:

0 Chamado para agir como um empreendedor da própria vida produz um modelo para as pessoas entenderem o que elas são e o que devem ser e lhes diz como trabalhar sobre si mesmas a fim de tornar-se o que devem ser. Em outras palavras, o self empresarial é uma forma de subjetivação. Como tal, a atividade empreendedora é menos um fato do que um campo de força. Ela é uma meta pela qual os indivíduos lutam, uma medida segundo a qual eles julgam sua conduta, um exercício diário para trabalhar sobre o self e, por fim, um gerador de verdade pelo qual eles chegam a conhecer a si mesmos. (BRÖCKLING, 2016, p. viii, grifos nossos). 
0 sujeito empreendedor é aquele que faz de toda a sua vida um empreendimento, procurando maximizar seu próprio capital humano para projetar conscientemente seu futuro e se tornar aquilo que deseja ser (FOUCAULT, 2004; GADELHA, 2009). Cria-se um modelo normativo de comportamento que se torna a base de uma nova forma de regulação das condutas. Como demonstra Bröckling (2016), o empreendedor não pode ser visto como um sujeito pronto, acabado, mas sim como um ente sempre em construção, em perpétuo devir. Na nova forma de governo das condutas, o objetivo não é mais disciplinar, instruir ou moralizar, mas incitar e gerenciar o espírito empreendedor dos indivíduos, a fim de assegurar produtividade máxima, inovação permanente e competitividade global.

$\mathrm{Na}$ racionalidade neoliberal, os indivíduos devem ser governados por meio de sua própria liberdade e de suas aspirações a valores como sucesso, felicidade, autorrealização e qualidade de vida. Para isso, o indivíduo-empresa deve ser forçado a escolher e a se responsabilizar por suas escolhas.

0 indivíduo-empresa, assim, não é um conceito descritivo, mas um conceito normativo e prescritivo. Não descreve o que o sujeito é, mas aquilo em que deve converterse para continuar participando da competição econômica e do jogo social. A adoção de uma atitude empreendedora diante da vida é vista como a condição mesma para a participação não só no mercado de trabalho, mas em todas as esferas da vida social. Dessa forma, o empresário de si mesmo não é somente aquele que gerencia seus investimentos em educação e sua carreira como se fosse uma empresa, mas também aquele que encara sua vida familiar, sua relação com a comunidade e sua cidadania como empreendimentos ou como partes de um empreendimento.

0 objetivo da pedagogia empreendedora é justamente o de condicionar os indivíduos desde a infância a se conceberem e se comportarem de acordo com tal modelo normativo. Nesse sentido, a pedagogia empreendedora implica uma individualização radical das práticas e objetivos pedagógicos, acarretando a perda de qualquer dimensão de solidariedade e perspectiva de cidadania, na medida em que o cidadão não pode ser apenas aquele que vive para seu mundo privado, seus anseios e sonhos particulares: deve ser aquele que participa da esfera pública e do "mundo comum", sem o qual a cidadania e a democracia não seriam possíveis (ARENDT, 2014).

A perda da cidadania também implica uma série de riscos para o indivíduo que é chamado a comportar-se e conduzir-se como uma empresa. No governo neoliberal das condutas, a cidadania deixa de ser pensada a partir da solidariedade social e passa a ser vista de acordo com o comportamento do consumidor, que usa seu poder de escolha diante de uma diversidade de opções disponíveis - o indivíduo-empresa se constitui e se afirma por meio de atos de consumo. Porém, o tipo de investimento que faz na condução de sua própria vida é distinto do ato de adquirir uma mercadoria, pois esse investimento é uma decisão com consequências a longo prazo que precisam ser cuidadosamente ponderadas e cujo sucesso depende da participação ativa do sujeito ao longo do tempo. Nesse sentido, o indivíduo-empresa deve fazer escolhas concernentes a seu bem-estar presente e futuro, com base numa "racionalidade atuarial", de acordo com a qual ele deve calcular a necessidade e os riscos do investimento em si mesmo, em momentos críticos da vida (PETERS, 2001, 2005). 
Assim, segundo a ótica da pedagogia empreendedora, o estudante que conclui o ensino médio deve considerar as perspectivas de valorização futura de uma profissão antes de escolher um determinado curso universitário. Da mesma forma, o profissional empregado deve se requalificar permanentemente para manter seu valor no mercado de trabalho, ou, se ficar desempregado, deve considerar investir em outra formação, ou numa pós-graduação, para garantir seu reingresso no mercado. Em suma, forma-se um espaço de liberdade regulada, no qual se torna possível um "governo remoto" mediante as escolhas reguladas e responsáveis de agentes autônomos e empreendedores (ROSE, 2012).

Nessa lógica da responsabilização individual e da negação da dimensão coletiva da educação, no entanto, por mais que o indivíduo se empenhe no esforço de aprender, se adaptar e modelar a si mesmo, nada lhe garante que ele colherá os frutos do sucesso, pois nenhuma quantidade de esforço é suficiente para exorcizar o risco do fracasso. 0 indivíduo empreendedor deve se responsabilizar por suas escolhas, tornando-se o corretor que calcula os riscos de seus investimentos em si próprio. $\mathrm{Na}$ linha do sociólogo alemão Ulrich Beck, podemos falar da constituição de uma verdadeira "sociedade de risco", em que o indivíduo se torna agente, planejador e diretor de sua vida (BECK, 2010). 0 risco é privatizado, e problemas sociais como desigualdade e desemprego são atribuídos à incapacidade dos indivíduos de serem empreendedores e de aprenderem com suas experiências para planejarem racionalmente o próprio futuro. Assim, as "contradições da desigualdade social emergem novamente como contradições entre momentos da vida no interior de uma biografia", ao mesmo tempo em que a "provisoriedade da qual se reveste o desemprego é a metamorfose da causalidade externa em culpa própria, de problemas sistêmicos em fracasso pessoal" (BECK, 2010, p. 139, grifos do autor).

As novas técnicas de gestão educacional, como a accountability (responsabilização), a individualização dos desempenhos, a cobrança de metas e a auditoria permanente por meio de avaliações em larga escala servem para permitir o cálculo, o monitoramento, o controle e a avaliação das organizações e dos comportamentos, com o objetivo de tornar manipulável o risco e a insegurança. Na sociedade de risco, os sujeitos precisam ser autônomos e empreendedores para poderem ser gerenciados. Todos devem permanecer constantemente em movimento, aprender a aproveitar as oportunidades e investir continuamente em si mesmos para valorizar seu capital humano e realizar seus projetos de vida. Em vista disso, na racionalidade neoliberal, com a reconfiguração do papel do Estado - que deixa de ser assistencial e "paternalista" -, o sujeito torna-se o único responsável por seu sucesso ou seu fracasso.

Portanto, o sujeito empreendedor está exposto a uma série de riscos sociais, que podem afetar brutalmente seu padrão material de vida, sua posição na sociedade e mesmo sua relação consigo mesmo: a flexibilização de direitos sociais e a diminuição dos mecanismos de proteção conduzem ao aumento da desigualdade e à crescente precarização da vida. Assim, a lógica da individualização da responsabilidade leva à crescente vulnerabilidade social (CARAHER; REUTER, 2017).

Além disso, o desemprego crescente de trabalhadores qualificados e portadores de diplomas de ensino superior põe em dúvida o vínculo estabelecido pelas teorias do capital humano entre escolarização, produtividade, competitividade e renda (DOWN, 2009). Esse 
fato mostra que, com frequência, o investimento em si do indivíduo-empresa não produz os resultados esperados. Vale ainda pontuar que nem todos possuem as condições sociais e psíquicas necessárias para vencerem no jogo da competição individualizada. Nesse sentido, precarização e a degradação das condições de emprego, com a "uberização" da economia (SLEE, 2017), põem em xeque o próprio valor normativo do modelo do indivíduo-empresa.

Diante da natureza cronicamente disfuncional do capitalismo financeiro, evidenciada após a crise global de 2008, o indivíduo-empresa acaba se revelando um ideal normativo frágil, porque é inatingível na prática. A lógica da responsabilização individual gera angústia, ansiedade, estresse e uma série de outras patologias (HAN, 2015). Nesse contexto da sociedade do risco individualizado, a fábrica do sujeito neoliberal converte problemas do sistema econômico e social em responsabilidades individuais (BECK, 2010; DARDOT; LAVAL, 2016). Em outras palavras, todos os custos da disfuncionalidade do sistema são transferidos para as costas do sujeito.

\section{Considerações finais}

Entendido como um modelo normativo cada vez mais presente nas sociedades contemporâneas, a adoção de uma atitude empreendedora deixa de ser uma opção e torna-se uma necessidade para as diferentes esferas da vida, sejam elas profissionais, sociais ou econômicas. Neste sentido, tão logo sejam feitos os investimentos no "desenvolvimento da capacidade empreendedora" (DOLABELA, 2003a, p. 55) de um indivíduo, maiores serão as chances de maximização do seu capital humano e de transformação da sua vida em um grande empreendimento que o conduza àquilo que ele deseja ser (ROSE, 1998).

Esse entendimento fortalece e propaga a ideia de que "um dos mais poderosos meios de desenvolver o empreendedorismo em uma sociedade é por meio de programas educacionais" (DOLABELA; FILION, 2013, p. 135). Mais do que isso, para a racionalidade neoliberal, interessa a eliminação de toda e qualquer rigidez - inclusive psíquica -, e isso afeta as diferentes instituições, incluindo a escola (LAVAL, 2004). Portanto, não surpreende a proliferação de programas voltados para a disseminação do empreendedorismo na educação escolarizada e o enaltecimento do princípio da pedagogia empreendedora em diferentes meios sociais.

Como não poderia deixar de ser, na pedagogia empreendedora, a formação torna-se uma função atribuída ao estudante, que deve se responsabilizar por sua própria aprendizagem. Aprender permanentemente faz parte do espírito empreendedor (BALL, 2013), e isso implica adotar uma atitude de aprendiz em todos os espaços e nos diferentes ciclos da vida. Neste caso, mais do que aprender conteúdos, propósitos e relações (BIESTA, 2018), o que importa é desenvolver um conjunto de habilidades, "aprender a conhecer", "aprender a fazer", "aprender a conviver" e "aprender a ser" (DELORS, 2012).

Conforme o modelo normativo de comportamento, que é pressuposto pela pedagogia empreendedora e fundamenta as intervenções da iniciativa privada na educação, desenvolver a capacidade de se manter em constante processo de aprendizagem torna-se uma das condições para o indivíduo se tornar empregável e manter-se em condições de empregabilidade no 
futuro. Mais do que isso, tal postura é fundamental não só para que o indivíduo aprenda a ser flexível e a adaptar-se às diferentes situações que lhe são apresentadas, mas também para que ele realize seus sonhos e materialize seus projetos de vida.

Esse modelo, porém, como tentamos demonstrar, possui justamente aí sua maior fragilidade. Nem todos têm condições de se manter à altura dessa norma de comportamento inatingivel, e muitos verão seus sonhos naufragarem no fracasso escolar e profissional, bem como na consequente precarização da vida. Nesse sentido, o foco no protagonismo do estudante e na responsabilização individual produz fragmentação social, solapa as estruturas da cidadania e os mecanismos de solidariedade coletiva. Portanto, aumenta brutalmente a vulnerabilidade dos indivíduos e os riscos sociais, principalmente daqueles em condições de desvantagem socioeconômica. Assim sendo, esse modelo, não serve para pensar uma sociedade mais justa e uma educação mais inclusiva - compreendida como bem comum, e não como investimento privado em capital humano. Entendemos que, embora a adequação aos modos de vida que se impõem na atualidade seja uma necessidade, importa a manutenção da escola como espaço e tempo coletivos, de cidadania e de igualdade, e não como fábrica de subjetividades neoliberais para a nova economia.

\section{Referências}

ARENDT, Hannah. A condição humana. Rio de Janeiro: Forense Universitária, 2014.

BALL, Stephen. Aprendizagem ao longo da vida, subjetividade e a sociedade totalmente pedagogizada. Educação, Porto Alegre, v. 36, n. 2, p. 144-155, maio/ago. 2013. Disponível em: http://revistaseletronicas. pucrs.br/ojs/index.php/faced/issue/view/697. Acesso em: 12 jul. 2019.

BALL, Stephen. Educação global S.A.: novas redes políticas e o imaginário neoliberal. Ponta Grossa: UEPG, 2014.

BECK, Ulrich. Sociedade de risco: rumo a uma outra modernidade. São Paulo: Editora 34, 2010.

BIESTA, Gert. 0 dever de resistir: sobre escolas, professores e sociedade. Educação, Porto Alegre, v. 41, n. 1, p. 21-29, 2018. Disponível em: http://revistaseletronicas.pucrs.br/ojs/index.php/faced/article/ view/29749. Acesso em: 12 jul. 2019.

BOLTANSKI, Luc, CHIAPELLO, Ève. 0 novo espírito do capitalismo. São Paulo: Martins Fontes, 2009.

BRÖCKLING, Ulrich. The entrepreneurial self: fabricating a new type of subject. London: Sage, 2016.

CARAHER, Kevin; REUTER, Enrico. Vulnerability of the "entrepreneurial self": analysing the interplay between labour markets and social policy. Social Policy and Society, [S. I.], v. 16, n. 3, p. 483-496, fev. 2017. Disponível em: https://doi.org/10.1017/S1474746417000033. Acesso em: 12 ago. 2019.

DARDOT, Pierre; LAVAL, Christian. A nova razão do mundo: ensaio sobre a sociedade neoliberal. São Paulo: Boitempo, 2016. 
DELORS, Jacques (coord.). Educação: um tesouro a descobrir. São Paulo: Cortez; Brasília, DF: Unesco, 2012.

DOLABELA, Fernando. Empreendedorismo, uma forma de ser: saiba o que são empreendedores individuais e coletivos. Brasília, DF: Agência de Educação para o Desenvolvimento, 2003b.

DOLABELA, Fernando. Fernando Dolabela: pedagogia empreendedora, empreendedorismo na educação básica e universitária. [S. I.: s. n., 2018?]. Disponível em: https://fernandodolabela.com.br/2018/07/17/ ensino-convencional-x-educacao-empreendedora/ Acesso em: 26 mar. 2021.

DOLABELA, Fernando. Pedagogia empreendedora. São Paulo: Cultura, 2003a.

DOLABELA, Fernando; FILION, Louis Jacques. Fazendo revolução no Brasil: a introdução da pedagogia empreendedora nos estágios iniciais da educação. Revista de Empreendedorismo e Gestão de Pequenas Empresas, São Paulo, v. 3, n. 2, p. 134-181, set./dez. 2013.

DOWN, Barry. Schooling, productivity and the entrepreneurial self: beyond market values. Critical Studies in Education, [s.I.], v. 50, n. 1, p. 51-64, fev. 2009. Disponível em: https://doi. org/10.1080/17508480802526652.Acesso em: 12 jul. 2019.

DRUCKER, Peter. Innovation and entrepreneurship. London: Routledge, 2012.

FOUCAULT, Michel. Malfazer, dizer verdadeiro. São Paulo: Martins Fontes, 2018.

FOUCAULT, Michel. Naissance de la biopolitique: cours au Collège de France. 1978-1979. Paris: Gallimard, 2004.

GADELHA, Sylvio. Governamentalidade neoliberal, teoria do capital humano e empreendedorismo. Educação \& Realidade, Porto Alegre, v. 34, n. 2, p. 171-186, maio/ago. 2009.

HAN, Byung-Chul. Sociedade do cansaço. Petrópolis: Vozes, 2015.

HAYEK, Frederich A. Competition as a discovery procedur. In: HAYEK, Frederich A. New studies in philosophy, politics, economics and the history of ideas. London: Routledge, 1978. p. 179-190.

JA BRASIL. Junior Achievement Brasil. A Junior Achievement: JA Brasil, Membro da JÁ Worldwide. Junior Achievement, Porto Alegre, [2018?]. Disponível em: https://www.jabrasil.org.br/sobre-nos. Acesso em: 26 mar. 2021.

KLAUS, Viviane. Efeitos no cotidiano escolar. [S. I.]: CNPq, 2018. Relatório da pesquisa gerencialismo e empresariamento da educação em escolas públicas do Rio Grande do Sul.

LAVAL, Christian. A escola não é uma empresa: o neoliberalismo em ataque ao ensino público. Londrina: Planta, 2004.

LÓPEZ-RUIZ, Osvaldo. Os executivos das transnacionais e o espírito do capitalismo: capital humano e empreendedorismo como valores sociais. São Paulo: Azougue: Fapesp, 2007. 
MARÍN-DÍAZ, Dora Lilia. Autoajuda, educação e práticas de si. Belo Horizonte: Autêntica, 2015.

MENGUE, Agnes Piangers. Pedagogia empreendedora: um estudo sobre o empresariamento de si a partir da metáfora do sonho. 2019. Dissertação (Mestrado em Educação) - Universidade do Vale do Rio dos Sinos, São Leopoldo, 2019.

MISES, Ludwig von. Human action: a treatease on economics. Auburn: Mises Institute, 2010.

PETERS, Michael. Education, enterprise culture and the entrepreneurial self: a foucauldian perspective. Journal of Educational Enquiry, [S. I.], v. 2, n. 2, p. 58-71, 2001.

PETERS, Michael. The new prudentialism in education: actuarial rationality and the entrepreneurial self. Educational Theory, [S. I.], v. 55, n. 2, p. 123-137, 2005.

ROSANVALLON, Pierre. 0 liberalismo econômico: história da ideia de mercado. Bauru: Edusc, 2002.

ROSE, Nikolas. Governando democracias liberais avançadas. In: MLLLER, Peter; ROSE, Nikolas. Governando o presente: gerenciamento da vida econômica, social e pessoal. São Paulo: Paulus, 2012. p. 238-260.

ROSE, Nikolas. Inventing ourselves: psychology, power and personhood. Cambridge: Cambridge University Press, 1998.

SCHUMPETER, Joseph A. Capitalismo, socialismo e democracia. São Paulo: Unesp, 2017.

SEBRAE. Serviço Brasileiro de Apoio às Micro e Pequenas Empresas. Educação empreendedora no ensino fundamental. Brasília, DF: Sebrae, 2021b. Disponível em: https://www.sebrae.com.br/sites/ PortalSebrae/ufs/pe/sebraeaz/educacao-empreendedora,429191c67982e410VgnVCM1000003b74010 aRCRD Acesso: 26 mar. 2021.

SEBRAE. Serviço Brasileiro de Apoio às Micro e Pequenas Empresas. Pronatec empreendedor. Brasília, DF: Sebrae, 2021a. Disponível em: https://www.sebrae.com.br/sites/PortalSebrae/ufs/pe/sebraeaz/educacao-em preendedora,429191c67982e410VgnVCM1000003b74010aRCRD. Acesso em: 26 mar. 2021.

SENNETT, Richard. A cultura do novo capitalismo. Rio de Janeiro: Record, 2008.

SIBILIA, Paula. Redes ou paredes: a escola em tempos de dispersão. Rio de Janeiro: Contraponto, 2012. SLEE, Tom. Uberização: a nova onda do trabalho precarizado. São Paulo: Elefante, 2017.

TODOS PELA EDUCAÇÃO. Quem somos. São Paulo: Todos pela Educação, 2019. Disponível em: https:// www.todospelaeducacao.org.br/pag/quem-somos/. Acesso em: 02 ago. 2020.

Recebido em: 15.07.2019

Revisado em: 21.07.2020

Aprovado em: 01.09.2020 
Alexandre Alves é doutor em história econômica pela Universidade de São Paulo (USP), fez pós-doutorado em história cultural na Universidade Estadual de Campinas (UNICAMP) com estágio na Université Paris VIII e pós-doutorado em educação na Universidade do Vale do Rio dos Sinos (UNISINOS).

Viviane Klaus é Professora e pesquisadora no Programa de Pós-Graduação em Educação e no Mestrado Profissional em Gestão Educacional da Universidade do Vale do Rio dos Sinos (UNISINOS), doutora em educação pela Universidade Federal do Rio Grande do Sul (UFRGS.

Carine Bueira Loureiro é professora e pesquisadora no Programa de Pós-graduação em Informática na Educação do Instituto Federal Rio Grande do Sul (IFRS), doutora em educação pela Universidade do Vale do Rio dos Sinos (UNISINOS) e coordenadora do Grupo de Estudos e Pesquisa em Educação, Matemática e Tecnologias (GEPEMAT). 